\title{
Managing the Koala Problem: Interdisciplinary Perspectives
}

\author{
ELAINE STRATFORD, ${ }^{*}$ NICOLE MAZUR, $†$ DANIEL LUNNEY $\neq$ AND \\ DAVID BENNETT $\$
}

*School of Geography and Environmental Studies, University of Tasmania, Hobart, TAS 7001, Australia, email elaine.stratford@utas.edu.au

†Urban and Environmental Research Program, Research School of Social Sciences, Australian National University, Canberra, ACT 0200, Australia

‡New South Wales National Parks and Wildlife Service, P.O. Box 1967, Hurstville, NSW 2220, Australia

\Australian Academy for the Humanities, Garden Wing University House, Canberra, ACT 2906, Australia

\begin{abstract}
There is a complex scientific, ethical, and cultural debate in Australia about bow best to conserve koalas and their habitat. Despite the diverse array of management and research options promoted by scientists, wildlife agency staff, and koala advocates, there remains a gap in our acknowledgment of the social factors influencing decision making about koala conservation. Koala management research has generated valuable scientific knowledge about koala biology and ecology but bas been weak about organizational and policy processes and about the cultures within which we produce, disseminate, and legitimize this kind of knowledge. We suggest that more effective koala conservation will result from making the political and cultural influences on decision making regarding the koala more explicit in research, management, and policymaking forums. Research must be conducted in the context of the cultural significance of the koala. The koala's survival depends on preserving the valuable lands that these creatures (and many others) inhabit. Ultimately, the koala symbolizes conflicting land-use values and illustrates the need for greater collaboration, cooperation, and trust among social and natural scientists in the conduct of koala conservation research, management, and policy.
\end{abstract}

Manejo del Problema del Koala: Perspectivas Interdisciplinarias

Resumen: Existe un debate científico, ético y cultural en Australia sobre cómo conservar mejor a los koalas y sus hábitats. A pesar de las numerosas opciones de manejo e investigación promovidas por científicos, personal de las agencias de vida silvestre y defensores de koalas, aún existe una brecha en nuestro reconocimiento de los factores sociales que afectan la toma de decisiones sobre la conservación de koalas. La investigación sobre el manejo de koalas ba generado conocimiento científico valioso sobre su biología y ecología pero poca información sobre los procesos funcionales y políticos y sobre el entorno social en el que se produce, disemina y legitima este tipo de conocimiento. Sugerimos que se lograría una conservación más efectiva del koala si se bicieran más explícitas las influencias políticas y culturales que afectan la toma de decisiones respecto de los koalas. La investigación debe realizarse tomando en cuenta la trascendencia cultural del koala. La supervivencia del koala depende de la conservación de tierras valiosas habitadas por estos animales (y muchos otros). A fin de cuentas, el koala simboliza valores conflictivos de uso del suelo, y como tal, ilustra la necesidad de una mayor colaboración, cooperación y confianza entre científicos sociales y naturales en la investigación, el manejo y las políticas de conservación del koala. 


\section{Introduction}

The koala is central to some significant and often heated scientific, ethical, and cultural debates about conservation policy and research. Parties to these debates seek to clarify how the conservation of the koala and its habitats might best be achieved (Clark et al., this issue). We examined elements of culture and policy in the conservation of the koala through an interdisciplinary perspective. We established how the koala "problem" is represented and interpreted in popular culture and scientific discourse. We also considered how approaches to the koala have shifted over time, noting the transition from exploitation to current tensions between regional parochialism and national cooperation. In light of this discussion, we also examined how koala policy responses are manifest in different regions and at different levels of government in Australia. Finally, we devised recommendations for addressing this complex interdisciplinary problem.

We use methodological strategies derived from qualitative research in the social sciences (Eyles 1988; Patton 1990). We analyzed documentary evidence from government reports, scholarly literature, and popular culture, deliberating on how each contributes to the construction of the koala as a problem to be managed. We drew from the fields of cultural geography, policy research, wildlife ecology, and environmental philosophy. These diverse perspectives are important to the conduct of qualitative research, particularly given the need for triangulation strategy (Denzin 1978): the use of multiple data, investigators, methods, and theoretical frameworks to corroborate and verify research findings. Our analysis, then, is both catholic and eclectic, and it is meant to be so. It is not a scientific treatise written by people trained in scientific practice, but a meditation on a series of social, cultural, and policy issues related to the conservation biology of the koala.

\section{Setting the Context}

There are numerous Aboriginal myths and legends associated with koalas (Phillips 1990); here we confine our analyses to European cultural issues. Between European conquest and current times the management of koalas has dramatically shifted in purpose (Strahan 1986). The koala has been a focus of scientific interest, popular culture, and conservation since shortly after European conquest. Lee and Martin (1988) note that in the nineteenth century naturalists began transferring names of already familiar European animals to koalas, referring to them as sloths, monkeys, bears, even monkey bears. Naturalists executed many drawings of koalas, and there was an effort to document the koala's discovery, understand its anatomy, and assign it to a taxonomic group. By the early twentieth century, there was also growing interest in describing and analyzing koala physiology.

The koala was also an exploitable resource. Europeans used koala fur as a tradeable commodity, and hunting severely affected koala populations until the late 1920s when the trade ceased. This shift in attitudes and practices was likely linked to what Frawley (1994) views as a growing appreciation of Australia's unique natural heritage. It was not until much later, however, that scientists began to consider the species' distribution, which is important because such knowledge requires some ideas of population status, a form of "benchmarking" that contributes to debates about the koala's conservation status.

Little scientific literature was produced on koalas from the late 1930 s to the early 1950 s. From the mid-1950s through the 1960s, another wave of physiologically based research was undertaken, along with the first work on koala ecology. In the 1970s, there was a marked increase in koala research, initially focused on koala diseases. Links were also made to conservation through discussions about relevant legislation, distribution, and abundance, and the effects of urban development on koala populations. In the 1980s, scientific research continued to reflect interest in koala disease and behavioral ecology, alongside a growing emphasis on fieldwork. A pronounced and ongoing debate about the koala's conservation status also emerged, as reflected in the other papers in this section.

Overall, our historically exploitative approach to the environment and our generally poor track record in contemporary wildlife conservation have been due partly to our cultural conditioning and social priorities. This situation has been changing in recent years as more conservation scientists and their colleagues in other fields use an approach to solving biodiversity problems which includes attention to species, threatening processes, and habitats. The application of this approach to ecological problems in bureaucratic and political settings may signal recognition of the multiple, intricate, and interrelated components of environmental degradation (Dryzek 1987; Paehlke \& Torgerson 1990; Doyle \& Kellow 1995). In some regions in particular, such change-in both scientific and political circles-has certain positive outcomes for the koala and other Australian wildlife. Indeed, conservation biology is beginning to reflect a laudable change from traditional, discipline-bound strategies to more interdisciplinary efforts, and new forms of knowledge and new understanding of cultural relationships with nonhuman nature are being generated in this and related fields.

Concerns for koalas, however, do reflect numerous and often disparate values. For instance, rescue and rehabilitation programs for individual animals primarily concern animal-welfare issues. Initiatives to conserve koalas on the basis of compassion are informed by a belief in the rights of nonhuman nature, including ecosystems, to exist free from human interference. Alterna- 
tively, certain koala management programs, such as those recommending culling to "rebalance" koala populations, reflect principles of sustainability.

Koalas are also only one of many species in Australia currently considered by some to be threatened with extinction. Scientists who undertake research on koalas are often drawn into the wider conservation debate when they are asked to advise governments. The narrow issues of koala management include how to deal with over-browsing in Victoria and South Australia, with small populations in wood-chipped forests of southeastern New South Wales, and with the effects of bushfires or the outbreak and spread of chlamydia. The broader issues of conservation in which the koala is implicated include habitat protection and threatening processes.

The debate about listing the koala as nationally vulnerable exemplifies some of the difficulties in striking a balance between specialist and contextual studies-between the narrow and the broad. This debate could emanate in part from a reliance on reductive approaches to wildlife management problems when actual variety is warranted. As it stands, the koala has not met the national requirements for listing as a threatened species because its distribution and regional conservation status ranges from introduced pest in certain places to secure in some areas to vulnerable or extinct in others (Phillips 1990; Australian and New Zealand Environment and Conservation Council [ANZECC] 1998). In effect, attempts to standardize its status at a national level are confounded by the variety of its conditions at regional levels. State and territory frameworks and institutions for defining categories of threat, whether a species is vulnerable, rare, or endangered, may be too rigid and unable to accommodate local conditions. Only species that are "almost extinct" are accommodated within these frameworks because they occupy so little of the land surface of Australia. In contrast, the koala occupies considerable areas of land with major commercial potential.

The endangerment discourse raises another important question: Is the function of designating a species as endangered to prevent its extinction in the next 10 years or in the next 100 years? The koala is not likely to disappear over its total range within the next century, so it is unlikely to be listed as nationally endangered. The campaign to list the koala as endangered has been prompted by a belief that the approaches of state and commonwealth governments to koala conservation fail to address such thorny issues as restricting clearing on private land or curtailing highway developments and forestry.

The koala epitomizes the conflict of reconciling current land uses with the professed interest in saving wildlife. Its emotive appeal is substantial and provides many advantages for those attempting to raise community concern. Koalas can symbolize the need to retain remnant bush for the sake of native wildlife or the need to stem habitat loss; they are powerful icons for conservation. Nevertheless, a focus on charismatic species and governmental regions rather than on less attractive species and bioregions is highly problematic (Craig \& Stewart 1994; Recher 1994). What is it about popular and scientific cultures that tends to reductionism of one form or another, and what alternative traditions in science might point a way forward? A cultural analysis of the koala conservation problem may help answer this question.

\section{Cultural Analysis of the Koala Conservation Problem}

Defining the koala conservation problem is a challenge. Janet Weiss (1989:97) argues that "Problem definition is a package of ideas that includes, at least implicitly, an account of the causes and consequences of undesirable circumstances, and a theory about how to improve them." How problems are defined partly determines whether they are present or absent from the public agenda. Indeed, problem definition is a critical process in conservation policy. For instance, determining a species's conservation status can influence how it is managed, and labels such as vulnerable, rare, or endangered define a set of conservation problems.

Are koalas endangered? Certainly disease, hunting, predation, and loss of habitat have threatened their longterm viability. In some regions, though, the koala is considered a pest of plague proportions. Part of the dilemma of defining a problem-in this case, whether the koala requires particular and dramatic conservation assistance-stems from the fact that only certain definitions of the koala problem will prevail. This is because of the nature of political processes and other power relations and because of regional variation in conservation issues and possible responses to them. Part of the dilemma of problem definition also stems from the fact that participants in the discussion bring to the task different historical perspectives, personal opinions, and world-views.

\section{Popular Culture}

The koala has been a source of curiosity for naturalists, an economic boon for hunters, and a reservoir of inspiration for both scientific research and community action. In addition, the species has been popularized and commodified for decades. Various koala characters exemplify this popularity and commercial appeal: Norman Lindsay's storybook koala, Bunyip Bluegum (The Magic Pudding 1965), the Hanna Barbera cartoon the "Kwicky Koala Show," Dorothy Wall's Blinky Bill (1969), and Mem Fox's Koala Lou (1988).

Making these observations about the commodification of the koala begs the question of why the species is such 
a potent icon of Australian natural heritage and cultural identity. This power may go some way toward explaining why conservation and management of the species is fraught with political and social complexity. Therefore, it is important to consider the popular culture as part of an interdisciplinary approach to koala policy and management.

Bill Phillips' (1990:2) populist monograph on the koala summarizes how the creature has been perceived in the psyche of Europeans in bygone eras and in more recent times. Based on the language Phillips uses (1990:2), it is arguable that he contributes to the continuing anthropomorphism and commodification of the koala:

\footnotetext{
.. .what is it that makes koalas so popular, so adored? Is it their cheeky, unblinking stare, their childlike embrace or simply their cute and cuddly look? Whatever it is, there's no disputing the special affinity that we all feel with these remarkable animals. Gazing down from swaying eucalypts, chewing nonchalantly on tender young leaves, koalas appear unaffected, even indifferent to the world around.
}

As if to qualify the effect of this rhetoric, Phillips's (1990:3) next observation is designed to bring us back to earth: "However, as civilisation slowly closes in on their forest domain koalas can no longer take their peaceful existence for granted."

On South Australia's Kangaroo Island, such a version of disaster does not bear up under examination. There, koalas have been introduced into the forest domains of other species, and their own survival is threatened by overpopulation and tree defoliation. Even so, the prospect of koalas being culled on the island in 1996 prompted a public outcry, captured in headlines such as "Jo Beth: Don't Kill Our Koalas" (The New Post 1996). The Australian Koala Foundation's ambassador, Jo Beth Taylor, is also a television celebrity and musician, well known among Australia's commercial television audiences. Taylor argues that the problem with the management of koalas is not their excessive numbers but the decreasing numbers of trees. Her solution to what she calls the horrible and ridiculous proposal to cull koalas is to plant more trees. In general, this idea is laudable. Nevertheless, there are at least four problems with this solution. First, it is overly simplistic, taking no account of the ecological relationships involved. Second, it does not address the regional variance in koala numbers, distributions, and conditions. Third, complex details are often assumed by editorial staff to alienate the reader, so, as is characteristic of many popular magazines, detail and sophisticated argument are lacking. Finally, the report in The New Post is as much about Jo Beth Taylor as it is about the plight of the koala. The names of the programs in which Taylor stars are noted; de facto advertising is occurring. Moreover, the front cover shows a close-up photograph of an appealing Taylor cuddling an equally appealing juvenile koala. This image is likely to sell more copies of the issue than would a picture of a koala and reflects the commercial imperative to make sales and gain solid ratings.

Beyond texts that promote the koala, there are masses of koala toys, clothes and accessories, and internet sites to boost the animal's popularity and economic importance. It is significant that David Wotton, then State Minister for Environment and Natural Resources, made a strong connection between his decision not to cull the koala and the economic importance of the species. In 1997, he said, "There have been few issues that have attracted so much emotion . . . world wildlife groups, school children, parents, community groups, tourism associations and many, many others have continued to make representations to my office on this issue . . ." (Mayne 1997:28)

Wotton recognizes the commercial need to protect the koala, but the discourse by which he is constrained-the need for political expediency-is not always consistent with the research findings of conservation scientists (for example, the Koala Management Task Force 1996).

\section{The Culture of Science}

So how do these populist notions differ from scientific ideas about the koala and its management? We conceive of the term science in a broad sense as "systematized knowledge," and this definition embraces policy formulation, management, social research, and the basic and applied disciplinary sciences. We explored the construction of scientific knowledge in general, building a bridge from our understanding of traditional and popular perceptions of the koala to the kinds of knowledge produced about its conservation and management and the paradigms and practices that inform them. We sought to flesh out the ways in which conflicting values and interests (which are subjective and experiential, or cultural) are often reified in discourses on science (which can be deployed in ways that go beyond objectivity to rigidity).

Clark (1993) proposes that scientists need to think beyond their disciplinary boundaries to enhance the organizational and policy outcomes of conservation efforts. This assertion is one that many conservation biologists appear to agree with in principle, recognizing that ecological complexity demands interdisciplinarity cooperation. This collaboration is often difficult to achieve, however, in part because of the manner in which knowledge is produced, legitimized, and applied.

Since the mid-1950s, historians, philosophers, and cultural analysts of science have alerted us to the fact that knowledge is not absolute. Rather, it is subject to varying conditions and produces outcomes we cannot always predict. We explored some of the implications of this subjectivity for koala conservation by using insights adapted from Michel Foucault's (1972) book The Archaeology of Knowledge. In the appendix Foucault examines "the discourse on knowledge." He explains that knowledge is de- 
termined by the contexts in which it is produced. These include certain discursive rules about who can speak, for whom, about what, and in what situations. This work harks back to Weiss's (1989) observation about problem definition and the assertion that only certain definitions and management tactics flowing from them will prevail in our institutional and cultural settings. They are, in effect, rules on the discourse of science. They might be applied to koala conservation in several ways.

First, some arguments carry more influence than others do. Two ecological economists recently estimated that koalas contribute $\$ 1.1$ billion to the Australian economy through tourism (Hundloe \& Hamilton 1997). But in the differential power stakes between, for example, conservation and development interests, the latter tend to prevail because koalas are often represented in scientific discourses as somehow separate from their habitat, an object of analysis removed from its context. In wildlife parks, sequestered from their environments, koalas could continue to attract large sums of money. We could then "afford" to continue to disrupt and destroy habitat-and thus threaten the viability of ecosystems more generally - through, for example, urbanization and agricultural development. One dangerous message that emanates from this kind of false logic is that species conservation can be divorced from ecosystem preservation.

Second, other discourses are bestowed a certain privilege relating to two separate and distinct issues. Scientific discourses on koala conservation are often produced in privileged forums with specialist memberships. The Australian and New Zealand Environment and Conservation Council's National Koala Conservation Strategy (ANZECC 1998) was created by a relatively closed group that produces important policy. Furthermore, many koala symposia have taken place in the last 20 years (Bergin 1978; Lee et al. 1990; Lunney et al. 1990; Australian Koala Foundation 1995, 1996, 1997a, 1997b; Cork et al. 1995; Gordon 1996; Lunney \& Matthews 1997; Melzer et al. 1997). Next, it is important to acknowledge that there are occasions when conflicting values and interests regarding conservation in general and koala conservation in particular have meant that different interest groups form. The conservation outcomes of research, or the needs of species and ecosystems, are then considered secondary to proving which views are "correct" or more important. Here, privilege can be abused and the welfare of the koala can be further jeopardized.

Third, when we name or define koala endangerment as a problem, we confer a peculiar type of privilege on koalas. The decision to include the koala as vulnerable in New South Wales in 1992 (Lunney et al. 1996) exemplifies its elevated status. Koala conservation-as distinct from the conservation of habitats suitable for koalas and other species-can attract substantial funds, significant levels of public exposure, and considerable political clout. Where this species-based approach is used in iso- lation from policy and practices that account for threatening processes or ecosystems, individual koalas might be protected, but the plight of other species goes unaddressed. Popularity and appeal matter.

Fourth, another significant concern is that which is left unsaid or marginalized in debates about koala conservation. Habitat loss, fragmentation, degradation, overbrowsing, natural disasters, disease, roads, and predation are major factors in koala endangerment (ANZECC 1998). Yet economic rationalism, urban planning, and attendant issues of property rights (land speculation and profiteering), the domination of transportation by private vehicles, and the careless management of domestic pets underlie habitat-based issues of koala endangerment. These cultural matters nevertheless appear too complex and too difficult to address and are usually sidelined in the koala policy debate when they should be central.

Fifth, certain rules and fellowships exist in koala conservation. Conservation managers possess formal qualifications, join various organizations, and understand and participate in the verbal and other rituals of these institutions. In effect, they are inside the discourse and can have a considerable effect on koala conservation and other conservation management decisions. This position exists among those studying koala conservation and wildlife management more generally and can also be found in other conservation discourses on forestry, mining, or aquaculture. Although we are not suggesting that formal training is inappropriate, we know that local, community-based knowledge can be insightful and helpful in conservation, and it is used increasingly in conservation practices that take an interdisciplinary approach. Given that communities may not be fully versed in the complexities of official conservation knowledge, however, they may be marginalized from decision-making forums of professional institutions. Care must be taken to avoid these outcomes by including communities in traditionally privileged discourse.

Labinger (1995) points out that the cultural study of science has lacked input from scientists. He proposes that members of the scientific community should work more often with social scientists and cultural commentators on the characteristics and outcomes of various scientific methods and should make explicit the values that inform scientific work. Like Clark (1993), Labinger argues that scientific research should become more interdisciplinary. Interdisciplinary projects could enhance scientific management and practice by highlighting the unexamined assumptions that inevitably underlie koala conservation, for example. These biases also unwittingly narrow the range of outcomes of scientific work, perhaps by allowing consideration of too few options for the long-term preservation of koalas and the habitats they occupy.

The idea that our knowledge is always partial and contested is not new, and it does not come exclusively from outside of science. Heisenberg's Gifford lectures on quantum mechanics in 1957 (cited in Olson 1971) in- 
clude assertions that can be applied to the relationship between the culture of science and koala conservation.

First, many scientific efforts strive for certainty. There is no certainty about the conservation status of koalas, even though those involved in the political process might wish there were. This uncertainty is reflected in definitions of endangered, a term that changes from one piece of legislation to another. For example, in New South Wales under the Endangered Fauna (Interim Protection) Act 1991, all scheduled fauna were called endangered in either part 1 (threatened) or part 2 (vulnerable and rare). With its replacement by the Threatened Species Conservation Act 1995, the same schedules of fauna were collectively called threatened under the categories endangered or vulnerable. Thus, in New South Wales between 1992 and 1995 it was correct to call the koala endangered, but it was incorrect to call it threatened. In 1996 it became correct to call it threatened and incorrect to call it endangered (Lunney et al. 1996). Although these descriptions of conservation status are becoming standard among conservation professionals, they are used loosely in newspapers, politically driven conservation pamphlets, and other forums.

Second, all knowledge contains some degree of subjectivity. For example, our efforts in natural resource management are affected by personal and cultural understandings of the significance of the land and of its faunal and floral diversity. These conscious and subconscious perceptions then influence the way we conduct scientific and social investigations or implement and evaluate policies. On Kangaroo Island, for instance, Parks and Wildlife Service staff regularly observe and document ecological indicators of koala well-being: numbers, movements, distribution, breeding, morbidity and mortality, tree condition, and other environmental markers. The measurement itself may or may not be subjective, but the choice of what to measure is. The issue is that certain critical variables will not be measured. Hence, the emerging picture is not only biased but flawed.

Third, we spend much time and many resources studying the koala rather than naming, classifying, and changing the activities that we know endanger ecosystem integrity. So more science is not always equivalent to better science. In addition, producing management and policy documents does not automatically effect deep-seated linguistic and cultural change. How we think, speak, and write about wildlife management is important. Processes to develop and implement coherent conservation policies often falter because of the tacit and even unconscious values that conservation language contain. Furthermore, the defense that "we need to know more about the koala to be helpful" is legitimate, but it does not tackle those cultural conditions that facilitate the decline of the koala and its habitat. But knowing more about this species holds many challenges, not least of which are its regional variations, which characterize its status and the political and juridical contexts within which decisions about that status are made.

\section{Regional Policy and Management of the Koala}

The diversity of interest groups promoting koala conservation reinforces the idea that the koala is culturally significant for both Australian and international communities. Although most government wildlife agencies and nongovernmental koala preservation groups value koala conservation, policy and its influence is far from uniform. For the Northern Territory, Tasmania, and Western Australia, koala conservation is not an issue; the species occurs in these places only in wildlife parks and similar facilities. In the rest of Australia, there is significant variation in the conditions faced by koalas. Divergent values and strategies are also promoted by koala interest groups. Examining the distribution of koalas and the status of legislation that directly and indirectly affects the conservation of koalas across Australia is useful. This information illustrates how knowledge about koalas, their habitat, and their conservation is produced and translated into policy and management.

\section{Victoria and South Australia}

In Victoria and South Australia, koalas exist in similar conditions. In Victoria, koalas are widespread over much of the southern and eastern lowlands, and population densities are high in many areas. Koala densities tend to be lower in dry forests and woodlands in northern Victoria, where their habitat is less productive. Overall, koala habitat in Victoria is fragmented, isolating koala populations (Martin 1989; Clark \& Ahern 1995; ANZECC 1998). The Victorian Department of Natural Resources and Environment's koala policy relies on a draft management plan (Martin 1989). Most recently its staff has been trying new sterilization methods and continuing with the department's relocation program for koalas, although significant progress with this program has been confounded by resource shortages.

Koalas in South Australia occur over a greater range than was the case before European settlement (Koala Management Task Force 1996). Several sites are now under pressure because of high population densities, resulting in subsequent defoliation and death of trees, such as on Kangaroo Island (Koala Management Task Force 1996; ANZECC 1998). In South Australia, government policy has largely followed the Koala Management Task Force Report commissioned by the South Australian Government in 1996, when koala problems seized media headlines. The South Australian Management Plan of 1996 prescribes (1) conserving wild koalas within their former known range, (2) conserving introduced populations of koalas at densities consistent with the carrying capacity of ecosystems they inhabit, (3) involving government and nongovernment organizations in the design and implementation of koala policy, and (4) increasing community understanding of issues relevant to koala conservation (Department of Environment and Natural Resources 1996). 
The situation in South Australia and Victoria is paradoxical. In certain regions, the koala is disappearing in the face of widespread habitat loss and degradation, yet select populations are overbrowsing their limited food supply. Debates on koala management have been dominated by the question of how to address overpopulation, tree damage, and habitat loss leading to starvation. Nevertheless, koalas are a protected species in both states, and several comparable legislative mechanisms are, or can be, used to conserve koalas and their habitats. The extent to which these mechanisms are used to implement koala conservation is unclear, but most strategies have focused primarily on relocation (and more recently on fertility control) to relieve local density problems; culling remains unacceptable at this point.

\section{New South Wales and Queensland}

In New South Wales, the koala's original range has been reduced by $50-75 \%$, and remaining populations occur primarily on the north coast (Reed et al. 1990). Away from the coast, koalas are uncommon or rare, except in a few cases such as Gunnedah, where populations have increased. In Queensland, koalas still occur across most of their original range. Some of these populations are large and considered stable. In general, however, koalas are threatened by continued clearing and fragmenting of woodland and forest (ANZECC 1998).

The policy of the New South Wales government is to manage koalas and their habitat on public and private land according to principles of ecosystem management and biodiversity conservation (ANZECC 1998). The cultural importance of the koala to the community in New South Wales is illustrated partly by its official listing by the state government as a vulnerable species and by the requirement to prepare a koala recovery plan (Lunney \& Matthews 1997).

The recovery plan, now in preparation, will address koala conservation in conditions of conflict. Conflict arises as a result of decisions by government and private land owners on preserving remnant bush, using land for logging or farming, specifying the management of state forestry, highway construction, and so forth. The existence of these conflicts emphasizes the role of local government in identifying and conserving koala habitat through planning procedures (Lunney \& Matthews 1997). This approach is also consistent with the commonwealth government's interest in using community and local government as key participants in the process of conserving biodiversity (New South Wales National Parks and Wildlife Service 1997).

Queensland's koala management plans target the species in the wild and in captivity, provide funding and support for several intensive research programs to study koala conservation and rehabilitation, and establish stan- dards for the care of captive koalas. The Draft Management Plan for the Conservation of Koalas in Queensland was created in 1992. More recently, the 1995 State Planning Policy: Conservation of Koalas for regions around the Gold Coast was produced in a highly political context. Again in 1995, there was intense political debate over proposed clearing of remnant forest for a highway between Brisbane and the Gold Coast. The debate flowed into the 1996 state elections, in which the koala was appropriated as an icon of the bush and of species depending on those habitats.

Policies on koala management in Queensland and New South Wales reflect public perceptions of the koala as a species under threat. This situation results from the presence of highly active nongovernmental conservation groups, international koala-oriented tourism, a sizeable koala research community, and the media. In other words, the conservation of koalas is a high-profile issue involving many political stakes and many opinions about how such conservation might best be achieved.

\section{Australian Capital Territory}

The current status of the koala in the Australian Capital Territory is unknown. Anecdotal evidence suggests that there are relatively low population densities of koalas in the territory (ANZECC 1998). The primary policy concern of the Australian Capital Territory government is to manage captive populations of koalas.

\section{Federal Arena}

The federal government has responded to koala management by endorsing the need for a more coordinated approach to conservation. In November 1996, the draft National Koala Conservation Strategy was released by ANZECC amid controversy over the suggestions that the South Australian government would cull koalas on Kangaroo Island. Work on the strategy had begun in 1995 and, by 1998, a revised version was released which rejected culling as a management option. The strategy's primary aim is to conserve koalas by keeping viable populations in the wild throughout their natural range. It highlights greater integration of koala management among different levels of government as a key mechanism for realizing this aim.

The national strategy's very existence is perhaps its most interesting feature. The koala is not listed as a nationally threatened species, although it was nominated under the Commonwealth's Endangered Species Protection Act 1992. In 1997 a committee of scientists rejected this proposal, but the koala is recognized as a species in the "near threatened" category in the Marsupial Action Plan (Maxwell et al. 1996).

Current koala policies are characterized by diverse program objectives. For example, the National Koala Conserva- 
tion Strategy (ANZECC 1998) recognizes that conflicting land uses threaten koalas while acknowledging the significant role that communities play in conserving them. Yet in the strategy the lack of policy mechanisms for a national government to enforce its aims is not addressed. Instead, the strategy relies on states' responsibility for managing wildlife and on local government land-use planning and zoning schemes. Many related problems are identified nationally for the first time but remain unresolved. It is particularly problematic to define, map, and manage koala habitat and to manage accompanying threats such as bushfire, dog attacks, and death from cars.

\section{Summary}

These regional analyses raise policy and cultural questions that are at least as great as the issue of conserving koalas. Indeed, effective wildlife management is often confounded by conceptual and structural factors and by politicized decision-making processes. Such conditions call for flexible and diverse policy responses and management plans from both public and private sectors. Government and nongovernmental approaches to conservation make it difficult to implement the coordinated national strategy for protecting species and habitats. Australia's federalist system of government, and an emphasis on states' rights, limit better coordination among government agencies, particularly where conditions in each state vary.

Members of the research community cite the need for more scientific knowledge of koala biology, anatomy, reproduction, disease, distribution, abundance, and habitat. Although such information is essential, insufficient research is applied systematically to exploring cultures in which the problems of conservation are manifest. An example of this mismatch was the proposal to cull koalas on Kangaroo Island in 1996. This suggestion put scientific common sense in direct conflict with political and economic rationalism. Although considered more humane than leaving large numbers to eat out their habitats and to starve, culling was unacceptable because of the anticipated political and economic fallout both in Australia and overseas. What we are dealing with here are issues of culturehow we understand, give meaning to, represent, and redefine our relationship to species, habitats, and ourselves.

\section{Recommendations}

We suggest that the scientific project is less objective than it appears. We acknowledge that practicing scientists are aware of the political and cultural nature of knowledge production and policy formulation, and we argue that this realization is crucial to the survival of scientific participation in the debate. Indeed, it should be more vigorously embraced and made explicit in research, management, and policy.

Second, contemporary values and approaches to wildlife management insist that conservation efforts be directed to the protection of habitats rather than to individual species. This necessarily keeps the project of scientific research in the complex realm of politics and power relations.

Third, there needs to be an appreciation that policies formulated for the protection of koalas remain important, in part because of the iconic value of the species and in part because specialist's analyses of these animals remain valid. The latter should not be conducted out of context.

Reliance on scientific knowledge reflects our desire for a level of certainty in addressing problems such as koala conservation. When an environmental dilemma is defined as biological, conservation efforts can neglect critical nonbiological dimensions of conservation programs (Clark et al. 1994). Koala management research has generated valuable scientific knowledge about the species's biology and ecology, but needs to be clearer about organizational and policy processes and about the traditions and popular cultures within which knowledge is produced, circulated, and legitimated.

Wildlife conservation is highly political (Yaffee 1994), and decisions to allocate resources for saving certain species, and the institutional settings in which those decisions take place, reflect certain values. Koala management is a complex process in which many participants formulate, implement, and enforce policies.

Two outcomes from these political processes arise. Since the late 1980s, following a national koala survey, the difficulties associated with declining populations of koalas and those threatened by overbrowsing have been apparent. Yet, in general, official responses to koala conservation issues have been slow and only partially effective, tending to serve special interests and to furnish politicians and policymakers with welcome opportunities to avoid possible political retribution, economic fallout, and public criticism. There is justification for much greater collaboration, cooperation, and trust among social and natural scientists in the conduct of conservation research, management, and policy. Interdisciplinary collaboration is critical.

\section{Acknowledgments}

We wish to acknowledge assistance from J. Kirkpatrick, S. Darley, T. Clark, S. Cork, and two referees whose comments forced us to revisit and rethink elements of this paper. N.M. also wishes to extend thanks to the Mawson Graduate Centre for Environmental Studies, The University of Adelaide, for support during parts of this research.

\section{Literature Cited}

Australian Koala Foundation. 1995, 1996, 1997a, 1997b. The status of 
the koala. Proceedings of conferences on the status of the koala. The Australian Koala Foundation, Brisbane, Queensland.

Australia and New Zealand Environment and Conservation Council. 1998. National koala conservation strategy. Canberra, Australian Capital Territory.

Bergin, T. J., editor. 1978. The koala. Proceedings of a symposium on koala biology, management \& medicine. Zoological Parks Board of New South Wales, Sydney.

Clark, T. W. 1993. Creating and using knowledge for species and ecosystem conservation: science, organisations, and policy. Perspectives in Biology and Medicine 36:497-525.

Clark, T. W., and L. Ahern. 1995. Draft outline for a koala management plan: Victoria. Department of Conservation and Environment, Melbourne, Victoria.

Clark, T. W., R. Reading, and A. L. Clarke, editors. 1994. Endangered species recovery: finding the lessons, improving the process. Island Press, Washington, D.C.

Cork, S., S. Feary, and C. Mackowski, editors. 1995. Koala conservation in the south-east forests. Proceedings of an expert workshop. National Parks and Wildlife Service and State Forests of New South Wales. CPN Publishers, Canberra, Australian Capital Territory.

Craig, J. L., and A. M. Stewart. 1994. Conservation: a starfish without a central disk? Pacific Conservation Biology 1:163-168.

Denzin, N. 1978. The research act. 2nd edition. McGraw Hill, New York.

Department of Environment and Natural Resources. 1996. Management strategy for koalas in South Australia. Adelaide, South Australia.

Doyle, T., and A. Kellow. 1995. Environmental policy and policy-making in Australia. Macmillan Education Australia, South Melbourne, Victoria.

Dryzek, J. S. 1987. Rational ecology: environmental and political economy. Oxford University Press, New York.

Eyles, J. 1988. Interpreting the geographical world: qualitative approaches in geographical research. Pages 1-16 in J. Eyles and D. M. Smith, editors. Qualitative methods in human geography. Polity Press, Oxford, United Kingdom.

Foucault, M. 1972. The discourse on language: appendix. Pages 215237 in M. Foucault, editor. The archaeology of knowledge. Random House, New York.

Fox, M. 1988. Koala Lou. Puffin-Penguin, Melbourne, Victoria.

Frawley, K. 1994. Evolving visions: environmental management and nature conservation in Australia. Pages 216-234 in S. Dovers, editor. Australian environmental history. Oxford University Press, Melbourne, Victoria.

Gordon, G., editor. 1996. Koalas: research for management. World Koala Research, Brisbane, Queensland.

Hundloe, T., and C. Hamilton. 1997. Koalas and tourism: an economic evaluation. Discussion paper 13. The Australia Institute, Canberra, Australian Capital Territory.

Koala Management Task Force. 1996. Final report on koala management. Report to Minister David Wotton. Department of Environment, Adelaide, South Australia.

Labinger, J. 1995. Science as culture: a view from the petri dish. Social Studies of Science 25:285-306.

Lee, A., and R. Martin. 1988. The koala: a natural history. New South Wales University Press, Kensington.

Lee, A., G. Sanson, and K. Handasyde. 1990. The biology of the koala. Surrey Beatty and Sons, Chipping Norton, New South Wales.

Lindsay, N. 1965. The magic pudding. Angus \& Robertson, Sydney.
Lunney, D., and A. Matthews. 1997. The changing roles of state and local government in fauna conservation outside nature reserves: a case study of koalas in New South Wales. Pages 97-106 in P. Hale and D. Lamb, editors. Conservation outside nature reserves. Centre for Conservation Biology, University of Queensland, Brisbane.

Lunney, D., C. A. Urquhart, and P. Reed, editors. 1990. Koala summit: managing koalas in NSW. Proceedings of a 1988 conference. New South Wales National Parks and Wildlife Service, Hurstville.

Lunney, D., A. Curtin, D. Ayres, H. Cogger, and C. R. Dickman. 1996. An ecological approach to identifying the endangered fauna of New South Wales. Pacific Conservation Biology 2:212-231.

Mayne, M. 1997. The kindest cut. The Bulletin 13 May:28. Sydney, Australia.

Martin, R. 1989. Draft management plan for the conservation of the koala (Phascolarctos cinereus) in Victoria. Arthur Rylah Institute for Environmental Research, Department of Conservation, Forests, and Lands, Melbourne, Victoria.

Maxwell, S., A. A. Burbidge, and K. Morris. 1996. Action Plan for Australian Marsupials and Monotremes. Australasian Marsupial \& Monotreme Specialist Group \& IUCN Species Survival Commission. Wildlife Australia: Canberra, ACT.

Melzer, A., D. Lamb, and F. Carrick, editors. 1997. The management and research of non-urban koala populations. Koala Research Centre of Central Queensland, Central Queensland University, Rockhampton.

The New Post. 1996. Jo Beth: Don't kill our koalas. 21 December:4-5. Melbourne, Australia.

New South Wales National Parks and Wildlife Service. 1997. New South Wales draft strategy for biodiversity conservation. New South Wales National Parks and Wildlife Service, Hurstville.

Olson, R., editor. 1971. Science as metaphor: the historical role of scientific theories in forming Western culture. Wadsworth Publishers, Belmont, California.

Paehlke, R., and D. Torgerson. 1990. Managing leviathan: environmental politics and the administrative state. Belhaven Press, London.

Patton, M. Q. 1990. Qualitative evaluation and research methods. Sage Publications, Beverly Hills, California.

Phillips, B. 1990. Koalas: the little Australian we'd all hate to lose. Australian National Parks and Wildlife Service, Australian Government Publishing Service, Canberra, Australian Capital Territory.

Recher, H. F. 1994. Why conservation biology: an Australian perspective. Pages 1-15 in C. Moritz and J. Kikkawa, editors. Conservation biology in Australia and Oceania. Surrey Beatty \& Sons, Chipping Norton, New South Wales.

Reed, P., D. Lunney, and P. Walker. 1990. Survey of the koala Phascolarctos cinereus (Goldfuss) in New South Wales (1986-87), with an ecological interpretation of its distribution. Pages 55-74 in A. K. Lee, K. A. Handasyde, and G. D. Sanson, editors. Biology of the koala. Surrey Beatty and Sons, Sydney.

Strahan, R. 1986. Black man, white man, koala. Wildlife Australia 23(1):22-25.

Wall, D. 1969. Blinky bill. Angus \& Robertson, Sydney.

Weiss, J. A. 1989. The powers of problem definition: the case of government paperwork. Policy Sciences 22:97-121.

Yaffee, S. L. 1994. The Northern Spotted Owl: an indicator of the importance of sociopolitical context. Pages 47-72 in T. W. Clark, R. P. Reading, and A. L. Clarke, editors. Endangered species recovery: finding the lessons, improving the process. Island Press, Washington, D.C.
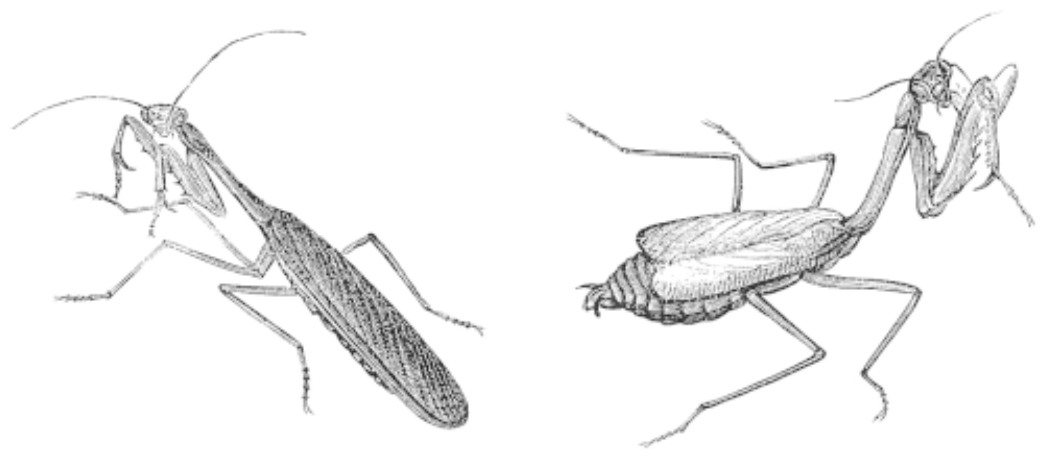